\title{
Protrusion of the posterior longitudinal ligament simulating herniated lumbar intervertebral disc
}

\author{
ROBERT A. BEATTY, OSCAR SUGAR, AND THEODORE A. FOX \\ From the Departments of Neurological Surgery and Orthopedic Surgery, \\ University of Illinois College of Medicine, and Illinois Masonic Hospital, \\ Chicago, Illinois, U.S.A.
}

The most common cause of lumbar or sacral nerveroot compression probably is herniation of the nucleus pulposus. There are some patients with typical clinical-and even radiological-evidence of nerve root compression, however, in whom no herniation is found at operation; instead the nerve root is compressed by a fold in the posterior longitudinal ligament, and, when this is excised, there is

TABLE I

CLINICAL SUMMARY OF 13 PATIENTS

\begin{tabular}{|c|c|c|c|c|c|c|}
\hline Age & $\operatorname{Sex}$ & Occupation & Signs and symptoms & Operation & $\begin{array}{l}\text { Length of } \\
\text { follow-up }\end{array}$ & Late results \\
\hline 37 & $\mathbf{F}$ & Housewife & $\begin{array}{l}\text { Pain in right hip radiating to lateral } \\
\text { aspect right ankle. Absent right ankle } \\
\text { jerk. Hypaesthesia lateral aspect right } \\
\text { foot }\end{array}$ & $\begin{array}{l}\text { L5-S1 laminotomy right. } \\
\text { Fusion }\end{array}$ & $6 \mathrm{yr}$ & $\begin{array}{l}\text { Asymptomatic. Active } \\
\text { housewife }\end{array}$ \\
\hline 53 & $\mathbf{M}$ & Carpenter & $\begin{array}{l}\text { Pain left calf and foot. Atrophic left } \\
\text { calf }\end{array}$ & $\begin{array}{l}\text { Left L4-5 laminotomy and } \\
\text { foraminotomy }\end{array}$ & 5 yr & $\begin{array}{l}\text { Still has burning dysaes- } \\
\text { thesias in leg; no } \\
\text { impairment of bending }\end{array}$ \\
\hline 19 & $\mathbf{M}$ & Student & $\begin{array}{l}\text { Weakness and numbness right calf. } \\
\text { Weak right plantar flexion. Hypaes- } \\
\text { thesia lateral aspect right foot }\end{array}$ & Right L5-S1 laminotomy & 4 yr & $\begin{array}{l}\text { Mild back pain with } \\
\text { activity }\end{array}$ \\
\hline 48 & $\mathbf{F}$ & Housewife & $\begin{array}{l}\text { Low back pain into left leg. Decreased } \\
\text { left ankle jerk. Hypaesthesia lateral } \\
\text { left foot }\end{array}$ & $\begin{array}{l}\text { Left laminotomy, L4-5, } \\
\text { L5-S1. Foraminotomy L4-5 }\end{array}$ & - & Lost to follow up \\
\hline 34 & $\mathbf{F}$ & $\begin{array}{l}\text { Factory } \\
\text { worker }\end{array}$ & $\begin{array}{l}\text { Low back pain. Left paraspinal spasm. } \\
\text { Hypaesthesia dorsum left foot }\end{array}$ & $\begin{array}{l}\text { Bilateral laminotomy L4-5, } \\
\text { L5-S1 }\end{array}$ & 4 yr & No back pain \\
\hline 33 & $\mathbf{M}$ & Steel worker & $\begin{array}{l}\text { Low back pain. Straight leg raising } 30^{\circ} \\
\text { on right }\end{array}$ & $\begin{array}{l}\text { Right laminotomy L4-5, } \\
\text { L5-S1. Transdural approach } \\
\text { to L4-5. Fusion }\end{array}$ & 3 yr & $\begin{array}{l}\text { Less strenuous job. Pain } \\
\text { in leg and low back } \\
\text { improved }\end{array}$ \\
\hline 35 & $\mathbf{M}$ & $\begin{array}{l}\text { Newspaper- } \\
\text { man }\end{array}$ & $\begin{array}{l}\text { Low back pain into left leg. Left } \\
\text { straight leg raising limited }\end{array}$ & $\begin{array}{l}\text { Left laminotomy L4-5, } \\
\text { L5-S1. Fusion }\end{array}$ & 3 yr & $\begin{array}{l}\text { Back at work; no leg pain; } \\
\text { occasional mild backache }\end{array}$ \\
\hline 30 & $\mathbf{M}$ & $\begin{array}{l}\text { Dock } \\
\text { worker }\end{array}$ & $\begin{array}{l}\text { Low back pain into left leg. Weak } \\
\text { dorsiflexion left foot }\end{array}$ & $\begin{array}{l}\text { Left laminotomy L4-5, } \\
\text { L5-S1 Fusion }\end{array}$ & 3 yr & $\begin{array}{l}\text { Working as dockhand. } \\
\text { Mild leg and lumbar pain. } \\
\text { No weakness }\end{array}$ \\
\hline 37 & $\mathbf{F}$ & Housewife & $\begin{array}{l}\text { Low back pain into right leg. Absent } \\
\text { right ankle jerk. Bilateral weak foot } \\
\text { dorsiflexors }\end{array}$ & $\begin{array}{l}\text { Bilateral L4-5 laminotomy. } \\
\text { Fusion }\end{array}$ & $2 \mathrm{yr}$ & $\begin{array}{l}\text { Occasional mild leg and } \\
\text { low back pain. No } \\
\text { weakness }\end{array}$ \\
\hline 40 & $\mathbf{F}$ & Housewife & $\begin{array}{l}\text { Low back pain into right leg. Hypaes- } \\
\text { thesia lateral right foot }\end{array}$ & $\begin{array}{l}\text { Bilateral L5-S1 laminotomy. } \\
\text { Fusion }\end{array}$ & $1 \mathrm{yr}$ & $\begin{array}{l}\text { Asymptomatic; no straight- } \\
\text { leg raising impairment }\end{array}$ \\
\hline 41 & $\mathbf{M}$ & Businessman & $\begin{array}{l}\text { Low back pain into right leg. Decreased } \\
\text { right ankle jerk. Limited right straight- } \\
\text { leg raising }\end{array}$ & $\begin{array}{l}\text { Bilateral laminotomy L4-5, } \\
\text { L5-S1. Fusion }\end{array}$ & 11 months & $\begin{array}{l}\text { No impairment of bend- } \\
\text { ing; straight-leg raising } \\
\text { normal }\end{array}$ \\
\hline 15 & $\mathbf{M}$ & Student & $\begin{array}{l}\text { Low back pain into right foot. Weak } \\
\text { right foot dorsiflexors }\end{array}$ & $\begin{array}{l}\text { Right laminotomy L4-5, } \\
\text { L5-S1 }\end{array}$ & 8 months & $\begin{array}{l}\text { No list, bends well, no } \\
\text { pain, no muscle spasm; } \\
\text { straight-leg raising normal }\end{array}$ \\
\hline 44 & $\mathbf{M}$ & Dairy & Low back pain into left leg. Absent & Left laminotomy L5-S1 & 8 months & s No back or leg pain \\
\hline
\end{tabular}




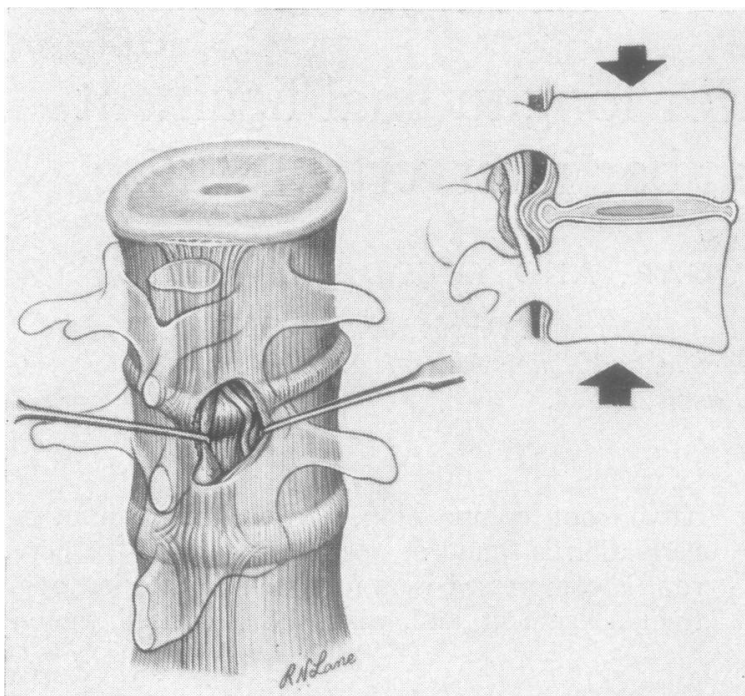

FIG. 1. Drawing of operative exposure showing protruded posterior longitudinal ligament over which the nerve root is stretched. Inset shows redundant ligament when disc space is narrowed.

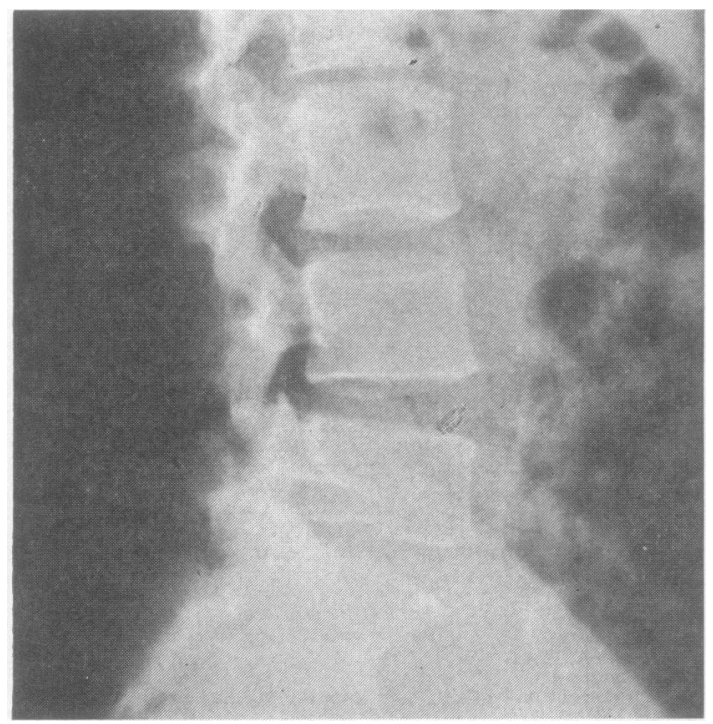

FIG. 2. Lateral view of lumbar spine showing what appears to be a normal L 4-5 interspace. Note the overriding facets narrowing the nerve-root foramen.

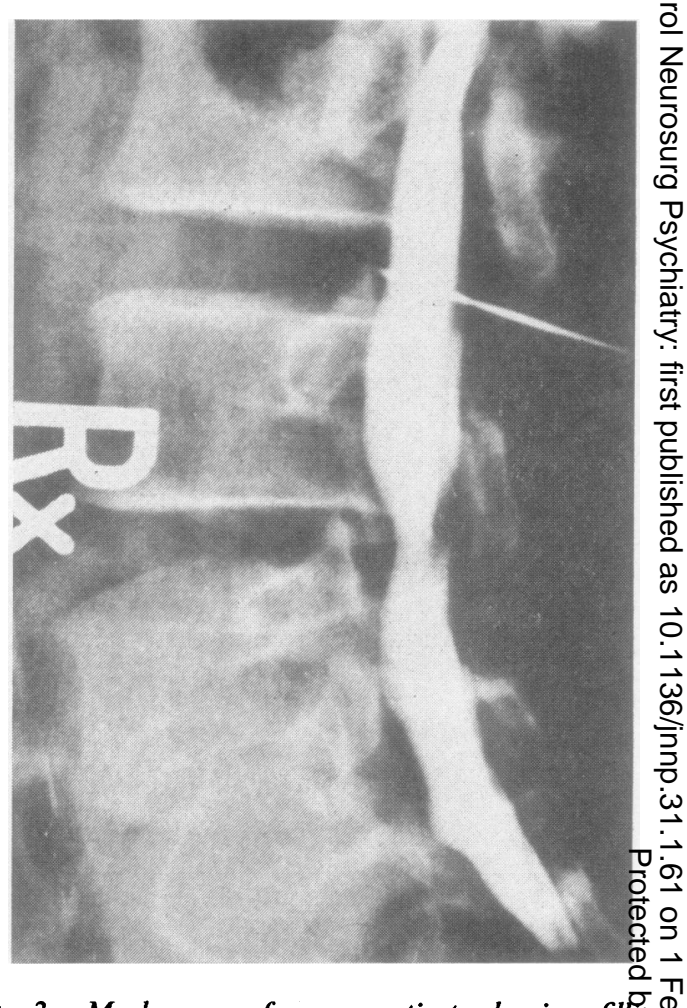

FIG. 3. Myelogram of same patient showing filing defect at the L 4-5 interspace.

little or no intervertebral disc material to be fouñ in the interspace. We are reporting a series of $13^{\circ}$ such patients.

\section{CLINICAL MATERIAL}

PREOPERATIVE EVALUATION Thirteen patients were drawri from both neurosurgical and orthopaedic practices (Table I). The duration of symptoms before operation varied from two months to 13 years, with the majority at three years. Ten patients related the onset of theic symptoms to a specific episode of trauma, usually? bending or lifting. Low back pain radiating into one leg was present in 10, and into both legs in two. In three, the initial complaint was calf or hip pain. There were objective signs of nerve-root compression (hypaesthesia depressed stretch reflex, weakness) in 11 patients, whilę two showed only limitation of straight leg raising on the affected side, in addition to persisting complaints of sciatica.

Narrowing of the appropriate intervertebral disc space corresponding to the radicular signs was demonstratew on plain radiographs of the lumbosacral area in seven of. 12 patients (one set of films was inadvertently destroyed) N Myelography was performed in six patients, five of whom had abnormalities. In three of these, there were unilaterap 


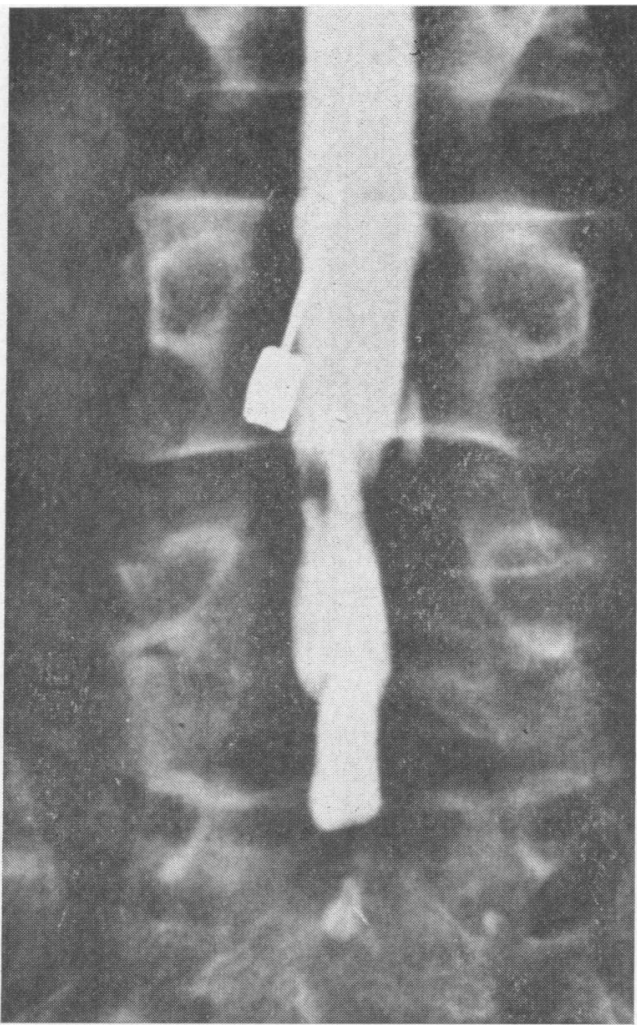

FIG. 4. Posterior-anterior view of same myelogram.

filling defects in the column of contrast medium, while, in two, bilateral defects were found. Electromyography (EMG) carried out in 11 patients showed evidence of lower lumbar or first sacral radiculopathy in nine. When the nerve root indicated by EMG corresponded to the clinical picture, Pantopaque myelography was not always done, for it is our opinion that one does not operate because of a positive or negative myelogram.

OPERATION This was carried out with the patient prone, sometimes with the legs dropped into a kneeling position, and under general endotracheal anaesthesia. After removal of the ligamentum flavum and as much laminar edge as was needed for exposure, the dural sac was retracted and the nerve root visualized, mobilized, and retracted (Fig. 1). The bulging posterior longitudinal ligament was incised and the disc space entered. The amount of cartilaginous material (disc and cartilage plate) was always scant and never protruding. The nucleus pulposus was practically non-existent. In some patients, the interspace was so narrowed that only a small curette (No. 0 or 1) could be inserted. Thorough curettage was always carried out. The part of the bulging ligament, over which the nerve root was stretched, was exised. If the level explored was between the fourth and fifth lumbar vertebral bodies, the next lower level

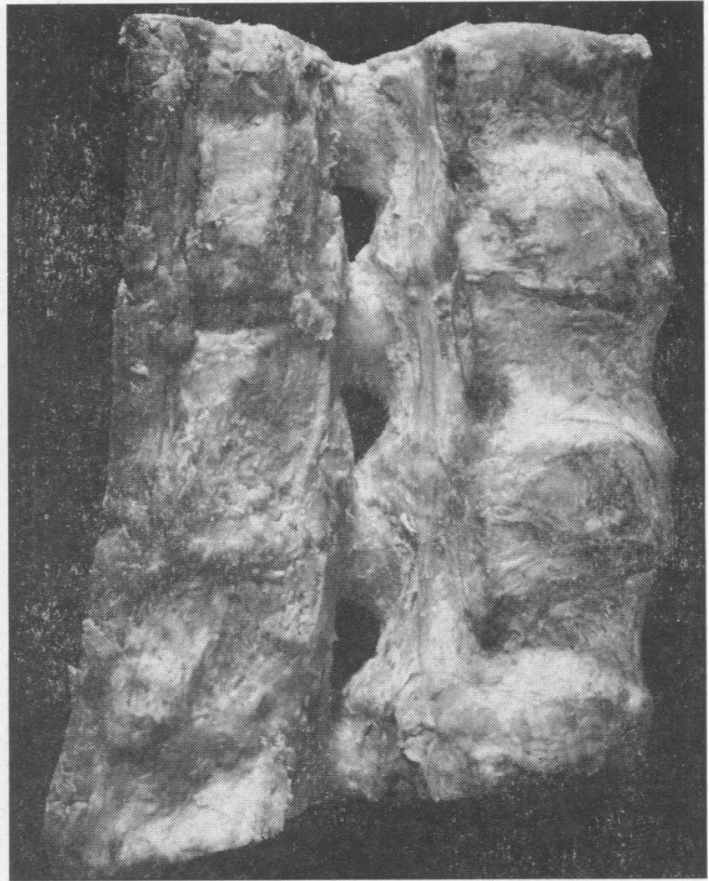

FIG. 5. Cadaver lumbar canal after removal of laminae and pedicles on one side.

was also explored (and vice versa), to assure the absence of a typical herniated nucleus with false localization. In seven patients, spinal fusion was carried out by the orthopaedist with an $\mathrm{H}$-shaped iliac graft interposed between the spinous processes of the fourth lumbar and first sacral vertebrae. The material removed from the disc space was usually degenerated cartilage, compatible with degenerated intervertebral disc.

We have followed cases as long as six years postoperatively. In 1966, five patients in the series were reexamined, and a questionnaire was sent to the others. One was lost to follow-up. All patients reported that they were improved and were either asymptomatic or were experiencing only mild backaches. None of the patients examined demonstrated limitation of straightleg raising or paraspinal muscle spasm. Hypaesthesia and depressed stretch reflexes tended to persist, however.

\section{CASE REPORT}

The syndrome is illustrated in the following typical case report. T.T., a 30-year-old dock worker, developed low back pain with radiation into the left leg following an automobile accident two years previously. Persistence of pain and weakness of the left foot led to hospitalization. The most striking finding was weakness of the dorsiflexors of the left foot. Plain radiographs of the spine (Fig. 2) showed straightening of the normal lumbar lordotic curve, retained height of the intervertebral 

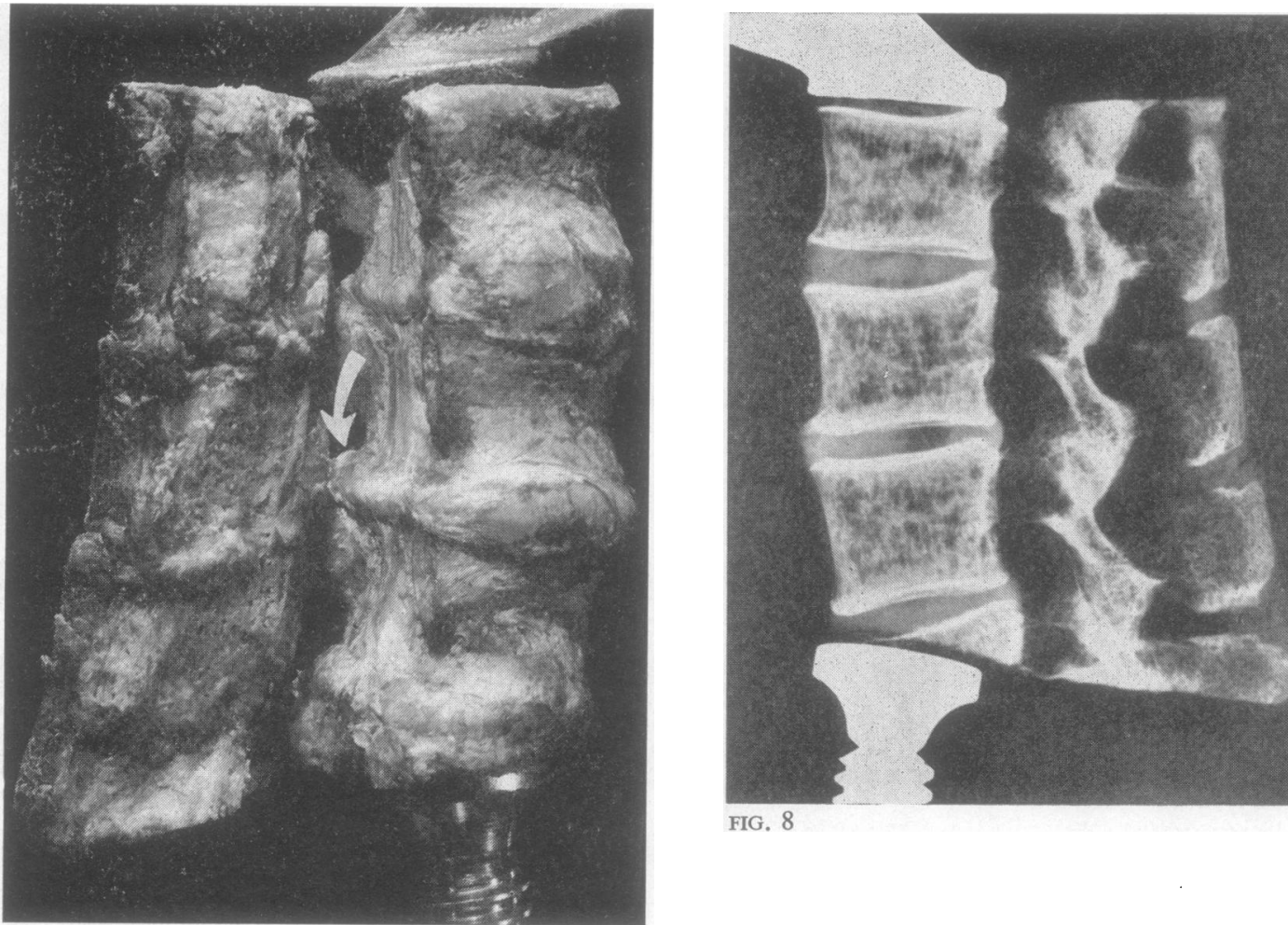

FIG. 8

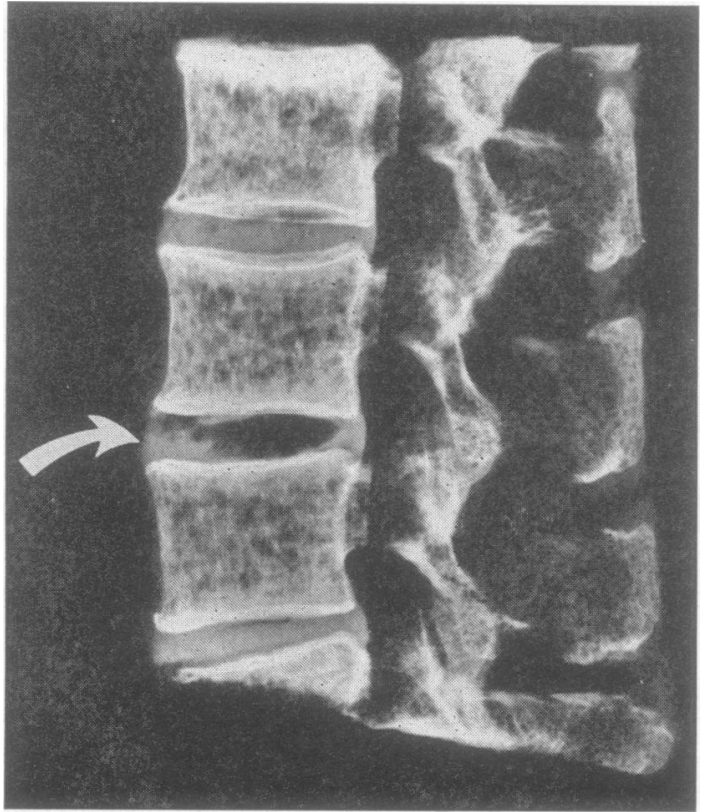

FIG. 6. Same specimen as Fig. 5 after removal of ome
nucleus pulposus and application of longitudinal com pression. Note marked bulge of posterior longitudirit ligament (arrow), slight bulge of ligamentum flavum, and narrowing of nerve-root foramen.

FIG. 7. Radiographs of lateral view of cadaver lumb氶 spine after removal of nucleus pulposus (from in front, ot arrow).

FIG. 8. Same specimen as in Fig. 7 with longitudinal compression applied. Note narrowing of intervertebral disc space. 
spaces, but overriding of the facets at the L 4-5 interspace, with narrowing of the intervertebral foramen. Myelography (Figs. 3 and 4) demonstrated filling defects at this interspace, especially on the left; EMG was not done. Operation revealed nerve-root compression at the L 4-5 interspace by a bulging posterior longitudinal ligament under which there was scant disc material. This was removed, and the bulging ligament excised; the spine was fused because of the apparent instability of the facet joints. When last seen, three years later, the patient was working as a dock hand and experiencing only minimal low back pain and no weakness of the left ankle.

ANATOMICAL STUDIES In an attempt to reproduce in a cadaver what occurs clinically, we removed the lower three lumbar vertebrae intact and, through the anterior longitudinal ligament, removed the nucleus pulposus of the intervertebral disc. Photographs and radiographs were taken before and after longitudinal compression was applied to the vertebrae by an ordinary woodworking 'C' clamp.

There was marked bulging of the posterior longitudinal ligament, narrowing of the nerve root foramen, and slight bulging of the ligamentum flavum into the spinal canal (Figs. 5 and 6). Radiographs (Figs. 7 and 8) showed narrowing of the affected interspace and slight overriding of the facets when compression was applied.

\section{DISCUSSION}

The anatomy of the intervertebral disc and its surrounding structures has been discussed in other publications (Larmon, 1944; Coventry, Ghormley, and Kernohan, 1945). Several related features should be emphasized. The posterior longitudinal ligament is attached only at the disc and passes loosely over the vertebral body. It is thickest medially and thins as it fans out laterally to blend with the annulus fibrosus (Hanraets, 1959; Hadley, 1964); some physicians even doubt its presence laterally. We have observed it laterally, where, along with the annulus fibrosus, it forms the anterior border of the intervertebral foramen. We have referred here to this fused structure as the posterior longitudinal ligament.

The mechanism of the degenerative disc has been reviewed by Saunders and Inman (1940), Hanraets (1959), and by Rabinovitch (1961). Briefly, the nucleus pulposus dessicates with age, allowing the disc space to narrow and causing the surrounding ligaments to become lax. In the herniated disc syndrome, the laxity of the ligaments places stress on the annulus fibrosus, which tears and causes the nucleus pulposus to herniate through the weakest point (posterolaterally where the foetal vessels to the disc originally travelled).

On the other hand, in the degenerative disc syndrome, a different mechanism must be at work. To account for the negligible disc material one must suppose an extreme degree of dessication, herniation of material through fissures in the cartilage plates into the vertebral bodies, or a congenital lack of disc material. The last two possibilities seem unlikely, first, because we saw no Schmorl's nodes and, secondly, because redundant ligaments could hardly be expected in congenitally narrowed discs. Moreover, it would be difficult for such a disc to herniate through the annulus fibrosus (Hanraets, 1959).

Various explanations have been proposed to account for radicular symptoms in the absence of a protruded disc. Most explanations have blamed structures which might narrow the nerve root foramen. Elsberg (1913) and Love and Walsh (1940) emphasized the significance of a thickened ligamentum flavum as it encroaches on the foramen posteriorly. With narrowing of the disc space, it is not inconceivable that the ligament could fold into the lumbar canal and the intervertebral foramen; here, for all practical purposes, it would become part of the posterior wall and cause nerve root compression (Fig. 8).

Hadley $(1938,1964)$ has shown that narrowing of the disc may cause subluxation of the facet joints and narrowing of the intervertebral foramen (Fig. 6). In fact, this may be the earliest radiological finding before narrowing of the disc space is apparent (Harris and Macnab, 1954).

Friberg (1941), on the other hand, contends that simple narrowing of the disc space cannot produce nerve root compression because the bony frame is too large to permit it. He has shown that the two lowest lumbar foramina are the smallest, while the corresponding nerves are the largest and are the only ones that pass directly over the disc. Narrowing may cause retropulsion of one vertebral body on its neighbour, thus decreasing the intervertebral foramen. In general, the interlumbar facets are in a sagittal plane, and the lumbo-sacral facets are in a coronal plane. However, these lower facets are often asymmetrical or are in a sagittal plane which may allow retropulsion (Armstrong, 1965). These anatomical facts may account for radicular symptoms in the face of slight changes in the intervertebral foramina.

Dandy described the 'concealed disc' in which there is a small amount of disc material and no protrusion of the disc. Adhesions between the nerve root and the posterior ligaments are said to account for the symptoms (Dandy, 1941; O'Connell, 1943). We did not encounter this condition in our patients.

Others have reported protrusion of the annulus fibrosus in patients with narrowed intervertebral 
discs. Mixter (1937) described both a unilateral and a general bulging of the whole edge of the disc, causing radicular symptoms which he treated by facetectomy or by 'trimming' where it seemed to compress the nerve root.

Bradford and Spurling (1945) doubted that a generalized protrusion was a frequent cause of the characteristic clinical picture of ruptured annulus fibrosus. They felt that facetectomy is preferable to attacking an intact annulus. However, it is unlikely that facetectomy in our patients could correct the bulging ligament lying anterior to the nerve and over which the nerve is stretched rather than compressed.

Friberg (1941) described a series of patients quite similar to ours. Of 58 patients undergoing exploration for symptoms of herniated disc, seven had only protrusion of the annulus fibrosus. Five of these had narrow disc spaces and abnormal myelograms. Two had filling defects in the midline, while three had filling defects laterally. Although there is a semantic difference between this series and ours, it is likely that they are pathologically identical.

For several years, we have performed spinal fusions in addition to resecting the redundant posterior longitudinal ligaments. The fundamental problem is an unstable back with narrowed interspaces, overriding facets, tilted vertebrae causing laminae to 'shingle' under one another, and buckled interlaminar and posterior longitudinal ligaments. Instability of the back sufficient to require fusion is defined by a long history of back pain with or without sciatica, aggravated by bending, and usually relieved temporarily by a lumbo-sacral support. In all patients in this series in whom fusion was performed, instability was demonstrated when, at the time of operation, the spinous process below the disc concerned was grasped and moved up and down and from side to side.

Narrowing of the disc space and overriding facets on the plain films before operation were considered in the decision to fuse the spine. However, as Begg and Falconer (1949) have shown, narrowed disc spaces on plain films are difficult to identify unless the diverging $x$-rays are parallel to the opposing vertebral surfaces. This special technique was not carried out in our patients, so the actual incidence of narrowed interspaces is not known. A narrowed interspace alone is no indication for fusion. When it is present with other clinical and operative evidence of instability, it is further argument for fusion.
There is insufficient material to warrant a valiक comparison of the diagnostic value of a myelos gram versus an electromyogram in this conditions The significant point is that either test may show results that are indistinguishable from those confo monly associated with patients who have protrude intervertebral discs.

SUMMARY

We have reported 13 patients with clinical syn dromes of lumbar or sacral nerve-root compression? in whom operation failed to reveal herniated intere vertebral discs but whose clinical, radiologica $\frac{F}{5}$ and electromyographical changes could have bee caused by folding of the posterior longitudina ligament into the lumbar canal compressing the nerve root. Excision of the redundant ligaments with or without fusion, resulted in significant relief of symptoms in all cases. We believe that thisu pathological process may be one of several causative factors to be considered in the group of patients who should have protruded discs, but do not.

\section{REFERENCES}

Armstrong, J. R. (1965). Lumbar Disc Lesions, 3rd ed., p. 74. Livit

stone, Edinburgh.
Begg, A. C., and Falconer, M. A. (1949). Plain radiograph ${ }_{\text {in }}$ in intraspinal protrusion of lumbar intervertebral disks: a cofrelation with operative findings. Brit. J. Surg., 36, 225-239. $T$

Bradford, F. K., and Spurling, R. G. (1945). The Intervertebral Rs 2nd ed., p. 98. Thomas, Springfield, Ill.

Coventry, M. B., Ghormley, R. K., and Kernohan, J. W. (192s The intervertebral disc; its microscopic anatomy and pathole 8 栚 J. Bone Jt Surg., 27, 233-247.

Dandy, W. E. (1941). Concealed ruptured intervertebral disk Amer. med. Ass., 117, 821-823.

Elsberg, C. A. (1913). Experiences in spinal surgery. Observations upon 60 laminectomies for spinal disease. Surg. Gynec. Obstet 16, 117-132.

Friberg, S. (1941). Low back and sciatic pain caused by intervertebra disc herniation. Acta chir. scand., 85, Suppl. 64.

Hadley, L. A. (1938). Pathologic conditions of the spine. J. Amero Med. Ass., 110, 275-278.

Hadley, L. A. (1964). Anatomico-Roentgenographic Studies of thפ Spine, pp. 9, 174-178. Thomas, Springfield, Ill.

Hanraets, P. R. M. G. (1959). The Degenerative Back and Its Diffe $\overrightarrow{\bar{\sigma}}$ rential Diagnosis, pp. 137, 167, 175. Elsevier, Amsterdam.

Harris, R. I., and Macnab, I. (1954). Structural changes in the lumbar intervertebral discs. J. Bone. Jt Surg., 36B, 304-322.

Larmon, W. A. (1944). An anatomic study of the lumbosacral region in relation to low back pain and sciatica. Ann. Surg., 119:892-896.

Love, J. G., and Walsh, M. N. (1940). Intraspinal protrusion of inter vertebral disks. Arch. Surg. (Chic.), 40, 454-484.

Mixter, W. J. (1937). Rupture of the lumbar intervertebral disk. Ann? Surg., 106, 777-787.

O'Connell, J. E. A. (1943). Sciatica and the mechanism of the prom duction of the clinical syndrome in protrusions of the lumbap intervertebral discs. Brit. J. Surg., 30, 315-327. Rabinovitch, $\mathbf{R}$. (1961). Diseases of the Intervertebral Disc and its Surg
rounding Tissues. Thomas, Springfield, Ill.

Saunders, J. B. deC. M., and Inman, V. T. (1940) Pathology of the intervertebral disk. Arch Surg. (Chic.), 40, 389-416. 